Dallasega, P., Revolti, A., Follini, C., Schimanski, C.P., Matt, D.T. (2019). "BIM-based construction progress measurement of non-repetitive HVAC installation works." In: Proc. 27th Annual Conference of the International. Group for Lean Construction (IGLC), Pasquire C. and Hamzeh FR. (ed.), pp. 819-830. DOI: https://doi.org/10.24928/2019/0152. Available at: 〈www.iglc.net>.

\title{
BIM-BASED CONSTRUCTION PROGRESS MEASUREMENT OF NON-REPETITIVE HVAC INSTALLATION WORKS
}

\author{
Patrick Dallasega $^{1}$, Andrea Revolti ${ }^{2}$, Camilla Follini ${ }^{3}$, Christoph Paul Schimanski ${ }^{45}$, \\ Dominik Tobias Matt ${ }^{67}$
}

\begin{abstract}
Construction projects are often delivered over time and over budget. Deviations are often identified only during the finishing stages when improvement actions to recover from delays become limited. Building Information Modeling (BIM) will transform the construction industry to come in line with more digitally developed industries like manufacturing. However, up to now, BIM has been mainly used to support the information flow of the construction design process and limited effort has been invested to investigate how it could support the management of the construction execution process. The paper shows how BIM can be used to schedule and monitor non-repetitive construction tasks. The proposed approach shows how important information needed for scheduling (like the number of pieces to be installed in a certain location) could be extracted from the BIM model. Moreover, it shows how BIM could support a quantitative monitoring of the reached progress and how this information can be displayed in an intuitive way to the user. The approach was developed during the project COCkPiT (Collaborative Construction Process Management) and especially by collaborating with a Heating Ventilation and Air Conditioning (HVAC) company using as a case study a medium sized hospital construction project located in Northern Italy.
\end{abstract}

\section{KEYWORDS}

BIM, lean construction, progress monitoring, non-repetitive, visual management.

\footnotetext{
Assistant Professor, Faculty of Science and Technology, Free University of Bozen-Bolzano, Italy, patrick.dallasega@unibz.it

2 Research Assistant, Faculty of Science and Technology, Free University of Bozen-Bolzano, Italy, andrea.revolti@unibz.it

3 Research Associate, Fraunhofer Italia Research, Bolzano, Italy, camilla.follini@ fraunhofer.it

$4 \mathrm{PhD}$ Candidate, Faculty of Science and Technology, Free University of Bozen-Bolzano, Italy, ChristophPaul.Schimanski@natec.unibz.it

5 Research Associate, Fraunhofer Italia Research, Bolzano, Italy, christoph.schimanski@ fraunhofer.it

6 Head of Fraunhofer Italia, Fraunhofer Italia Research, Bolzano, Italy, dominik.matt @ fraunhofer.it

7 Full Professor, Faculty of Science and Technology, Free University of Bozen-Bolzano, Italy, dominik.matt@unibz.it
} 


\section{INTRODUCTION}

The delivery of projects on-time and within the original budget is often a challenging aspect in the construction industry. Budget overruns are often identified only during the finishing stages of a construction project when intervention options become limited. According to the authors, this is mainly caused by 1) the insufficient consideration of important information during the planning phase and 2) the inability to track the construction progress on-site in real-time.

Building Information Modeling (BIM) can be recognized as one of the main enabling technologies for digitizing the construction industry (Eastman et al. 2011). BIM holds great potential for sharing and visualization of information as well as for the consideration of changes in design and during the execution of a construction project (Forsythe et al. 2015; Jeong et al. 2016; Deshpande et al. 2014; Sacks et al. 2010). In fact, information is kept centrally in the model, which allows it to be shared transparently and to be accessed by all construction participants (Forsythe et al. 2015). According to (Alizadehsalehi and Yitmen 2016), "BIM can serve as a powerful baseline for progress tracking and for the visualization of discrepancies". In fact, because of its powerful ability to map the physical building into a digital environment BIM holds potential for the visualization of the construction progress because it can visualize and express information more intuitively (Jeong et al. 2016; Ding et al. 2012).

BIM will become mandatory in future construction projects. Considering the construction execution process, its management as well as the quantitative control of the progress holds great potential for efficiency improvements (Sacks et al. 2010; Jeong et al. 2016). Currently, in many cases after the design phase important information included in the building model are not used anymore during the execution of construction works. As a practical example, the total amount of components to be installed by a certain task on-site could be very useful to estimate in a reliable way the duration of the task itself.

The paper was developed within the COCkPiT (Collaborative Construction Process Management) research project and especially in collaboration with a Heating Ventilation and Air Conditioning (HVAC) company using as a case study a medium sized hospital construction project. The concepts of "pitch" and normalized workload approach (NWA) (Dallasega et al. 2016; Schimanski et al. 2018) represent the basis for this study. At this, the key factor is the "pitch" as the NWA's core element, which helps us to schedule, and monitor construction projects in a quantitative and timely way with a very high accuracy. However, preliminary attempts of application of the pitch in the HVAC-industry showed that the definition of a pitch for HVAC activities is not directly derivable. This is due to the large diversity of present activities, such as the installation of ventilation ducts or the laying wiring. Here the definition of a uniform unit of measurement, e.g. running meter or number of units, turns out to be very challenging. This is especially true since the activities within single task groups also prove to be explicitly non-repetitive. For example, horizontally running ventilation ducts as part of a ventilation system have to be planned and measured differently as the fire shutters or throttle valves located between those ducts. 
In addition to this high degree of divergence, the approach for defining the pitch for individual trades is based on the collaborative study of floor plans, sections and views, usually in 2D plan printout format. In the HVAC area in particular, the identification of the individual ducts and pipes of the various trades crossing each other is a sophisticated task. The difficulty also increases if black and white printouts are used as usual. A well-known approach to circumventing these problems is widely acknowledged through the use of 3D models, most often as an inherent part of a BIM model. In the context of determining the pitch, a BIM model can therefore be regarded as advantageous in two respects: 1) to better understand the actual structure to be built (Mehrbod et al. 2019) and 2) for the identified tasks, the quantities to be handled can be determined very precisely and directly by means of model-based quantity take-off. As a result, the elements of the individual construction stages can be identified very decisively and in any number of units.

The main aim of the article is to show the potential to use BIM not only for the design but also for managing the construction execution process. Special emphasis is set on which kind of information should be extracted from the BIM model to support the planning, scheduling and monitoring of HVAC construction works on-site. Moreover, the paper investigates if the approach will allow to inform early on if there are plan deviations in a way to apply improvement actions to recover from delays in time. The proposed concept was applied in an HVAC supplier company from Northern Italy by using as case study a medium sized hospital construction project.

\section{RELATED WORK}

Within the world of academic research, the bibliography dedicated to the BIM topic in the scope of design phases and project variants is nowadays more than ever investigated and consolidated. In fact, there are numerous articles and publications dealing with the advantages of BIM for design changes, the easy creation of elevations and sections and the storage of information within a single $3 \mathrm{D}$ model.

However, BIM has been less studied considering the support to the execution part. Up to now, few articles have been described the interaction of BIM with other methodologies for execution management. Khan and Tzortzopoulos (2014) presented the implementation of the Last Planner System (LPS) weekly work plans in two BIM-based building design projects to achieve better workflow, reduce the waste of time on-site and monitor in a better way the production variability. Rezaei (2015) showed how BIM can be used to have a better overview for his Location Based Scheduling (LBS) estimations in 5D (3D model, construction scheduling and cost assessment) in a case study of a Private Villa in North Cyprus. Findings of the article are that BIM and LBS can be easily synchronized leading to shorter costs and execution times.

More recently, BIM has started to be investigated as a supporting tool for project management and quality control on-site. In fact, the 4D BIM approach adds an extra dimension of information to a project in terms of scheduling data (Eastman et al. 2011). This data is added to components that are going to be installed as the project progresses. This information can be used to obtain accurate programme information and simulations showing how the project will develop in the future. However, usually 4D BIM models are used for pre-construction planning and not for managing the execution process. Matta et 
al. (2018) describe the use of BIM-based sheets as a visual management tool to provide task instructions to the field. The approach was applied to a Chilean hospital construction project and the achieved results were the fulfilment of deadlines thanks to a reduction of response times for information requests. However, the authors point out that simply applying the technology is not enough, but it is essential to use it within a Lean collaborative methodology (Matta et al. 2018).

Bhatla and Leite (2012) described the advantages of using BIM on-site, to provide documentation and information for the work teams about products and process activities, with a 3D/4D components visualization. Harris and Alves (2013) used a pilot site of a hospital construction project in Southern California in order to study and analyse the field operational activities that could potentially benefit from 4D BIM integration and the factors that could foster or hinder successful 4D application in the field. They showed that through 4D BIM, for example, transparency within information exchanges and on-site collaboration increased. This improved the scheduling for subcontractors, assisted with delivery of resources (like operators, equipment and materials), and reduced variability. Clemente and Cachadinha (2013) studied the implementation of an integrated project management approach to achieve the alignment of interests of all stakeholders towards a common project's schedule. Their results show how a combined BIM-Lean approach improved workflow in HVAC maintenance projects. More in detail, it supported an early change detection of objects between the design and the installation phase on-site in a daily level of detail.

From the literature review emerged that BIM has been investigated mostly as a support for quality control, to identify the discrepancy in design, and to program the activities sequence. Up to now, BIM is not viewed as a central database to collect important information needed and collected on-site as well as a tool used to visualize and share information about the status of a construction project. BIM is not yet used as a repository that can be systematically updated (and graphically detected) with information coming directly from the sites every day or week (e.g. verification of correct installations, reason for noncompletion or non-conformity reports).

\section{APPROACH}

The approach of normalizing workloads for uniform scheduling and measurement of different construction activities requires the definition of the so-called pitch for every task. The concept of pitching is derived from lean production in the automotive industry and describes the relation of quantities (expressed in the respective measuring unit [MU]) of the task j (e.g. $20 \mathrm{~m}^{2}$ of parquet) that the corresponding crew (with crew size $\mathrm{k}$ ) is able to install in the CA i (e.g. floor 1) to the scheduled time interval (e.g. one working day).

$$
\text { Pitch }_{\text {CA }_{i}, \text { Task }_{j}, \text { Crewsize }_{k}}=\frac{\text { Quantity }_{i j}\left[M U_{j}\right]}{\text { time interval }}
$$

The pitch serves to define collaboratively a consistent process model of the entire construction project, whose dependencies and constraints are used to generate accurate schedules. In terms of monitoring the construction progress on-site, the pitch allows for 
indicating whether and to which extent a daily or weekly goal of value-adding activities had been fulfilled. Figure 1 depicts schematically the proposed approach.

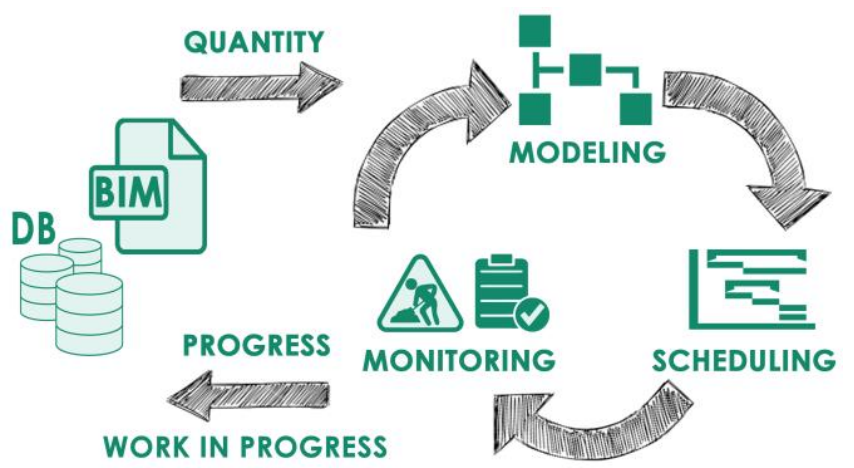

Figure 1: Description of the approach - BIM as supporting tool for construction management

Task-related quantities are derived from the BIM model for accurate estimation of the respective pitch during the modelling phase of the overall execution process. During scheduling, the amount of pitches is used to calculate the task durations and serve as orientation for the progress monitoring. For instance, a task that needs 100 pieces to install, having a defined pitch of 20 pieces per day with 2 workers results in a duration of 5 working days. In monitoring, the pitch provides orientation about the daily goal to be achieved in terms of quantities. The amount of actual installed pieces is fed back into the BIM model in order to visualize the reached construction progress.

Considering non-repetitive works like HVAC, the pitch can vary within one task according to the considered component to be installed. As a practical example, if we consider the task "installation of ventilation ducts", the installation of "straight channels" is different from the installation of "flow regulators" in terms of assembly mode. As such, the installation duration as well as the appropriate measuring unit needed to understand its completion degree could vary. The installation of "straight channels" might be measured in the installed surface (sqm) per crew per day and the installation of "flow regulators" might be measured in number of pieces per crew per day. As a result, to a specific task like "installation of ventilation ducts" different pitches can be assigned according to a specific class of components. To standardize the transfer of construction process related information between BIM models and construction management tools, the Industry Foundation Classes (IFC) file format can be used. IFC, which is prospectively considered to be a standard format for data exchange in an Open-BIM working environment (Dimyadi et al. 2008; Preidel et al. 2016), offers the possibility to describe process-related properties of all objects that comprise a BIM-model. This information is supposed to be stored in instances of the class IFCProcess and its subclasses (such as IFCTask) as part of the IFC data model (Borrmann et al. 2018). Consistent use of this provided storage space by all software systems involved in the BIM process, such as BIM authoring, coordination or scheduling software, would drastically streamline a BIM-based construction execution management and the exchange of process related information. According to the authors' 
experience, the various software solutions still rarely offer the possibility to access directly the IFCProcess classes of IFC files without the manual creation of new PropertySets. As a result, up to now, execution process related information as an immanent part of BIMmodels must be extracted manually and conditioned for the use on-site.

The integration of monitoring data with BIM is not only useful for quantity extraction, but also to intuitively visualize the construction progress. This may provide a twofold advantage for collaboration. On the one hand, it simplifies the input of the daily work performed based on the chosen pitch-measuring unit. On the other hand, it enables all actors, both from the same or other companies, to quickly understand progress issues. By consistently following the loop shown in Figure 1, the approach is aimed at a progressive refinement of the pitch value and, subsequently, at a higher reliability of the short-term scheduling. Therefore, a continuous application of the approach may improve transparency and planning, with the result of improving the overall installation workflow.

\section{RESEARCH METHOD}

This study follows an action research (AR) approach based on the application of the pitching methodology presented above. AR stands for the practical application of already developed approaches in order to solve a problem from practice for validating the applicability of the approach to this problem (Khan and Tzortzopoulos 2018). Based on findings of these applications it is foreseen to derive recommendations for future applications (Iivari and Venable 2009). According to AR's pioneer Lewin (1946), AR should follow multiple learning cycles, which consist of planning, acting and evaluating which is in line with the procedure of this research project. More in detail, this paper describes the application of the pitching methodology to a case study from the field of HVAC in one single learning cycle. In terms of monitoring, as one part of the pitching methodology, the progress data on site was collected through regular inspections on site by the authors. The monitoring data was analysed by means of a Microsoft Excel worksheet in terms of pitch deviation and fed back to the BIM model for visualizing the site status. This intermediate step of using Microsoft Excel will help to derive requirements for a direct application of BIM on site, which will be elaborated in the further course of this research project.

\section{CASE STUDY}

\section{CONTEXT}

The case study selected to validate the approach is a private healthcare facility specialised in rehabilitation and located in Northern Italy. It has a footprint of about 3500 sqm and it is composed of four levels aboveground and one level underground. The interior division of the building is rather complex, as it consists of living spaces and facilities with different purposes, such as medical rooms, generally hosting advanced technological equipment. This complexity is reflected on the HVAC system with little repetition of installation tasks. According to the project schedule, HVAC installation has an overall duration of 9 months, starting from October 2018 up to June 2019. 
The case study company subcontracted the HVAC installation task to an external company, while still managing the work, as well as providing HVAC shop drawings and components on-site.

The current process can be summarized as follows. First, the HVAC planner develops fabrication drawings, based on the execution plans. They consist of a $2 \mathrm{D}$ plan of the building floors, with a different code for each HVAC component, and 2D fabrication drawings to further detail the ducts. Ducts are produced off-site and delivered to the site with the needed accessories. Each piece has its code written upon it to easily recognize its position. The subcontracted company provides the billing in a monthly frequency according to the reached progress. More in detail, the billing is performed by the subcontracted company according to the surface of pipes (measured in square meters (sqm)) installed. As such, a difficult but important task of the project manager is to understand whether the progress reported corresponds to the real reached progress on-site.

Therefore, the HVAC company agreed upon a collaboration with the research institutes to analyse if BIM could be used to support in a quantitative way the measurement (in terms of surface in sqm) of the construction progress.

\section{APPlication OF THE APPROACH}

First, the Location Breakdown Structure was defined (Figure 2). It considers a horizontal view of the ventilation ducts as well as a vertical one for the risers. Considering the horizontal view, every level (from -1-5) was subdivided in 5 Construction Areas (CAs) according to their technology content. The CAs consist mainly of bedrooms, rehabilitation gym, swimming pool, offices and room with medical equipment. Moreover, CAs were defined in a way that each CA closes with an outward and return air duct as a closed system. Considering the vertical view, within every CA the risers were indicated with the acronym S.

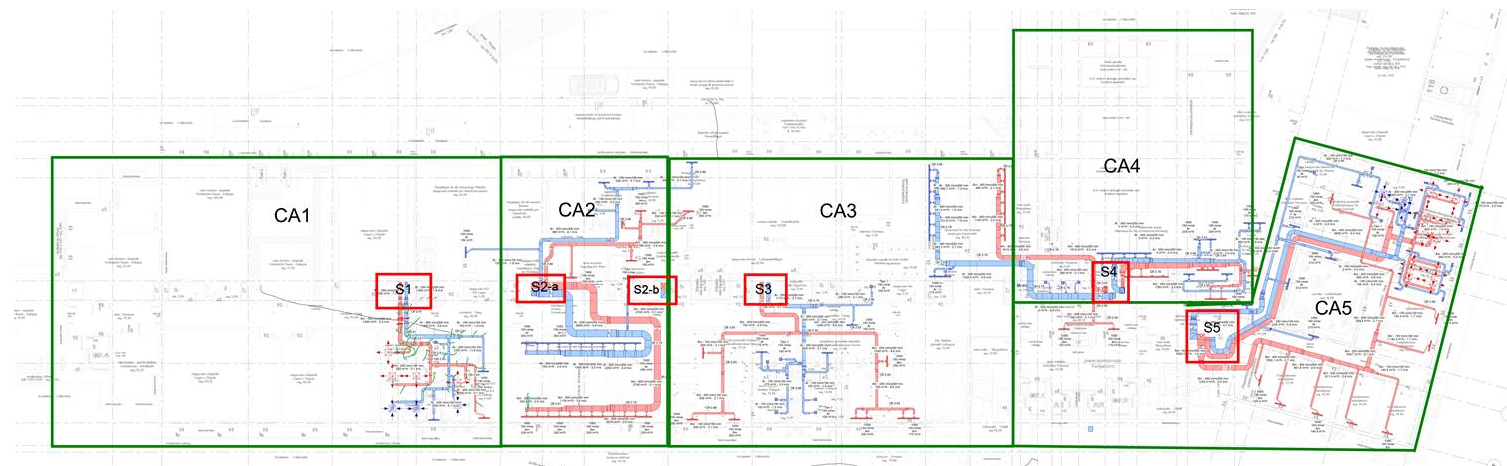

Figure 2: Development of the Location Breakdown Structure (LBS)

Together with the case study company, a meaningful frequency to monitor the installation progress in a weekly frequency was decided. Daily monitoring would provide data that is too fluctuating, and monthly monitoring data would not allow to react to deviations and recover from delays. Visits were performed on Fridays late afternoon, in order to map comprehensively the weekly progress.

The number of workers and the working hours, both necessary to calculate the deviation from the pitch, were retrieved from the daily construction diaries. 
Figure 3 shows the model in BIM of level 3 CA 5 developed with the software ArchiCAD version 22 as well as the weekly progress measurement on-site. The model was structured to extract the quantities and to visualize the construction progress. Air duct components were subdivided in two classes: 1) straight and curved sections of the pipes, where the unit of measurement is the total lateral surface, and 2) accessory elements such as flow regulators, nozzles, dampers, etc., for which the number of pieces is used as the measurement unit.
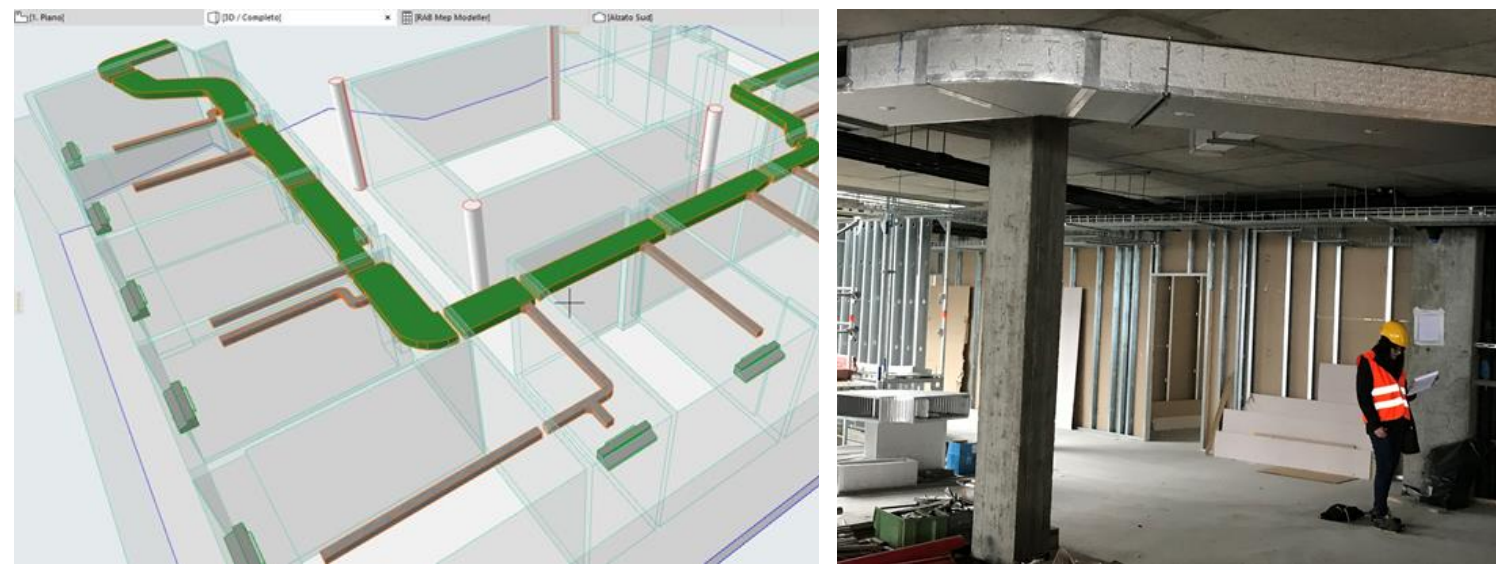

Figure 3: BIM model of level 3 and CA5 (progress reached until 15.02.2019)

To visualize the construction progress in an intuitive way in the BIM model a colourcoding consisting of five scales was applied. This was automatically done in the BIM software by using the functionality of "graphic overwriting" with specific rules and proprieties directly connected to the object tables.

To indicate the complete and correct positioning of pipes the colour green is used. To visualize any non-conformities (quality problems) components are marked in red. Components affected by a delayed installation are marked with orange and work in progress is visualized in yellow. Components that have not been installed are visualized in the colour grey.

The BIM model has been used to compare the weekly reached progress with the pitch calculated according to budget. Table 1 shows the calculation of the pitch for class 1 pipes.

Table 1: Calculation of pitch for straight and curved channels

\begin{tabular}{rrrcc}
\hline Class & Description & $\begin{array}{c}\text { Total lateral } \\
\text { surface }\left[\mathbf{m}^{2}\right]\end{array}$ & Duration [d] & $\begin{array}{l}\text { Pitch } \\
{\left[\mathbf{m}^{2} / \mathbf{2} \text { workers/day }\right]}\end{array}$ \\
\hline $\mathbf{1}$ & $\begin{array}{c}\text { Straight and curved } \\
\text { channels (pipes) }\end{array}$ & 9,680 & 280 & 34.57 \\
\hline
\end{tabular}

The daily pitch was calculated by using the total lateral surface in sqm of straight and curved channels to be installed and the required duration according to the project schedule $\left(9,680 \mathrm{~m}^{2} / 280\right.$ days $=34.57 \mathrm{~m}^{2} /$ day $)$. According to the foreman, a crew composed of two workers is usually performing this task. 
The monitoring sheet was configured in ArchiCAD and connected to the BIM model. Duct sections and accessories have been associated with a unique ID, based on the shop drawings provided by the case study company. Five columns have been dedicated to the weekly tracking: 1) Installation status, 2) non-conformity report (NCR), 3) time delay, 4) reasons for non-completion (RNC) and 5) tracking date. The monitoring sheet has been used to track the weekly progress and by importing it into the BIM software, it shows the tracked condition of the different components (reached construction progress).

As mentioned previously, the pitch has been computed in sqm for pipes and pieces for accessories (Figure 4). Therefore, to evaluate the first, a column with the lateral surface has been added to the monitoring sheet.

Figure 3 shows the example of the monitoring of CA5 in L3 in date February 152019. Progress has been registered on three Fridays: 11/01/2019 (week 1), 18/01/2019 (week 2), and 15/02/2019 (week 3). Since there has been no major delay or quality issue, it shows only two colours: green for the installed pieces and grey for the ones left.
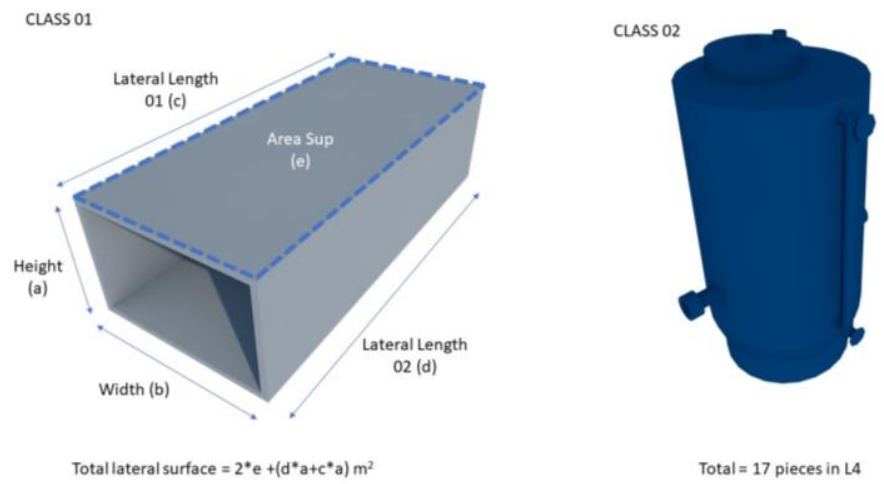

Figure 4: Class 01 pipes and class 02 accessories

Deviation from the pitch was calculated for the ducts of the first class (Table 2). The pitch of the component of the second class was used to reduce the overall number of working hours, to extract the effective used amount of work for just installing pipes. In particular, the overall time spent on class 1 elements in L3 CA5 was, respectively to the three monitoring weeks, 4.5 man-hours, 7.98 man-hours and 0.49 man-hours. Table 2 shows the calculation of the deviation from the pitch for the three monitoring weeks.

Table 2: Calculation of deviation from pitch for task "Installation of pipes" level 3 CA5

\begin{tabular}{lcccccc}
\hline & $\begin{array}{c}\text { Pitch budget } \\
{\left[\mathbf{m}^{2} / \mathbf{m a n}-\right.} \\
\text { hour] }\end{array}$ & $\begin{array}{c}\text { Time } \\
\text { worked } \\
{[\text { man-hour] }}\end{array}$ & $\begin{array}{c}\text { Quantity } \\
\text { budget } \\
{\left[\mathbf{m}^{2}\right]}\end{array}$ & $\begin{array}{c}\text { Quantity } \\
\text { built } \\
{\left[\mathbf{m}^{2}\right]}\end{array}$ & $\begin{array}{c}\text { Deviation } \\
{\left[\mathbf{m}^{2}\right]}\end{array}$ & $\begin{array}{c}\text { Deviation } \\
{[\text { man-hour] }}\end{array}$ \\
\hline week1 & 2.1875 & 4.42 & 9.67 & 8.056 & -1.61 & -0.74 \\
week2 & 2.1875 & 7.98 & 17.45 & 43.298 & 25.85 & 11.82 \\
week3 & 2.1875 & 0.49 & 1.07 & 15.666 & 14.60 & 6.67 \\
\hline
\end{tabular}

According to the calculation, the installation of pipes in level 3 CA5 was a little bit over budget the first week and much under budget the second and third week. However, because the subcontracted installation company did not work exclusively on level 3 CA5 the manhours spent in week 3 were not sufficient to reach a reliable calculation of the deviation to 
the pitch. According to a first feedback from the project manager of the case study company, the great potential of the approach is that it provides early warning signals to identify delays and deviations in time and as such, it increases budget security throughout the construction project execution.

Compared to the traditional use of a BIM model for the "quantity take-off" (to obtain information on size, number of pieces and so on) the proposed approach allows also to update information about the correct installation, achievable quality problems, delays with respect to the expected timing directly from the building site surveys.

\section{CONCLUSIONS AND OUTLOOK}

The paper shows how information extracted from BIM can be used to schedule and monitor non-repetitive construction tasks by the example of a HVAC case study company and the installation of air ducts in a private healthcare facility construction project. The fact that the installation of air ducts is a highly non-repetitive task makes the construction progress monitoring a challenging activity.

BIM showed to give support in the quantitative measurement of the construction progress. This was achieved by extracting the lateral surface (in square meters) of pipes installed, which allows to timely understand whether execution proceeds according to budget. It is important to note that, with the aim of optimizing the entire construction process, a unique BIM model has been created and used in the design phase, for the extraction of quantities, and, finally, to graphically show the progress of construction activities.

Preliminary results showed that the approach allows a weekly measurement of the reached progress and an evaluation if the project is over or under budget. Thanks to the graphical visualization of the reached progress in the BIM model, it allows an immediate and intuitive understanding of the status of a construction project, which may help easing planning, rescheduling and collaboration among the actors involved in the HVAC operations.

Future research consists of extending the validation of the approach to cover also accessories like valves or flow regulators. Moreover, other non-repetitive parts from HVAC, like water pipelines, will be considered that increase the difficulty for a visual recognition of installed parts on-site. Considering the last aspect, the research team started to investigate the potential for the development of a cognitive support by using BIM in combination with Mixed Reality (MR). Here, the interaction of MR with BIM in a way to record the progress of the installed objects and the indoor navigation to allow the overlapping of BIM with the real building will be investigated.

\section{ACKNOWLEDGMENTS}

The research presented in this article was carried out within the research project "Collaborative Construction Process Management (COCkPiT)" and financed by the European Regional Development Fund Investment for Growth and Jobs Programme 20142020 under Grant number 1008. The authors would also like to thank the involved companies Unionbau GmbH, Atzwanger AG and Frener \& Reifer GmbH for their valuable and non-remunerated contribution from a practitioner's perspective to the research project. 


\section{REFERENCES}

Alizadehsalehi, S., and Yitmen, I. (2016). "The Impact of Field Data Capturing Technologies on Automated Construction Project Progress Monitoring”. Proc. Eng., 161, 97-103.

Bhatla, A., Leite F. (2012), "Integration framework of BIM with the last planner system ${ }^{\mathrm{TM}}$ ", Proceedings for the 20th Annual Conference of the International Group for Lean Construction San Diego, pp. 1.10. Available at: www.iglc.net/Papers/Details/752

Borrmann, A., König, M., Koch, C., Beetz, J., (2018). Building Information Modeling Technology Foundations and Industry Practice. Springer.

Clemente, J., Cachadinha, N. (2013), "BIM-LEAN synergies in the management on MEP works in public facilities of intensive use - A case study". IGLC (2013) Fortaleza, Brasil, pp. 751-759. Avaiable at: http://iglc.net/Papers/Conference/23

Dallasega, P., Marcher, C., Marengo, E., Rauch, E., Matt, D.T. and Nutt, W. (2016) “A Decentralized and Pull-based Control Loop for On-Demand Delivery in ETO Construction Supply Chains." In: Proc. 24th Ann. Conf. of the Int'l. Group for Lean Construction, Boston, MA, USA, sect.8 pp. 33-42. Available at: 〈www.iglc.net>.

Deshpande, A., Azhar, S., and Amireddy, S. (2014). "A framework for a BIM-based knowledge management system". Proc. Eng., 85, 113-122.

Dimyadi, J., Spearpoint, M., Amor, R., (2008). "Sharing building information using the IFC data model for FDS fire simulation". In: Fire Safety Science. pp. 1329-1340.

Ding, L. Y., Zhou, Y., Luo, H. B., Wu, X. G. (2012). "Using nD technology to develop an integrated construction management system for city rail transit construction". Autom. in Constr., 21(7), 64-73.

Eastman, C., Teicholz, P., Sacks, R. and Liston, K. (2011). BIM Handbook: A Guide to Building Information Modeling for Owners, Managers, Designers, Engineers and Contractors, John Wiley \& Sons.

Forsythe, P., Sankaran, S., and Biesenthal, C. (2015). "How far can BIM reduce information asymmetry in the Australian construction context?". Proj. Manage J., 46(3), 75-87.

Harris, B., Alves, T.C.L. (2013). "4D building information modeling and field operations: an exploratory study”. Proceedings IGLC-21, Fortaleza, Brasil, pp. 811-820. Available at: http://www.iglc.net/Papers/Details/908

Iivari, J., Venable, J. (2009). "Action research and design science research - seemingly similar but decisively dissimilar". Special Issue of MIS Quarterly, 17th European Conference on Information Systems, Verona, Italy.

Khan, S., Tzortzopoulos, P. (2014). "Effects of the interactions between LPS and BIM on workflow in two building design projects". IGLC and Akademika forlag, Oslo, Norway, pp. 933-944. Avaiable at: http://www.iglc.net/Papers/Details/1004.

Khan, S., Tzortzopoulos, P. (2018). "Using Design Science Research and Action Research to Bridge the Gap Between Theory and Practice in Lean Construction Research". In: Proc. 26th Ann. Conf. of the Int'l. Group for Lean Construction pp. 209-219. Available at: <www.iglc.net>. 
Jeong, W., Chang, S., Son, J., and Yi, J., (2016). "BIM-Integrated Construction Operation Simulation for Just-In-Time Production Management”. Sustainability, 8, 1106.

Lewin, K. (1946). "Action Research and Minority Problems". Journal of Social Issues, 2, 34-46. http://dx.doi.org/10.1111/j.1540-4560.1946.tb02295

Matta, G., Herrera, R.F., Baladrón, C., Giménez, Z., and Alarcón, L.F. (2018) “Using BIMbased sheets as a visual management tool for on-site instructions: a case study." In: Proc. 26th Annual Conference of the International. Group for Lean Construction (IGLC), González, V.A. (ed.), Chennai, India, pp. 144-154. DOI: doi.org/10.24928/2018/0520. Available at: www.iglc.net

Mehrbod, S., Staub-french, S., Mahyar, N., and Tory, M., (2019). "Characterizing interactions with BIM tools and artifacts in building design coordination meetings". Autom. Constr., 98, 195-213.

Preidel, C., Borrmann, A., Dimyadi, J., and Solihin, W., (2016). „Towards code compliance checking on the basis of a visual programming language". J. Inf. Technol. Constr., 21, 402-421.

Rezaei, A. (2015). "Location Based Scheduling In The Form Of Flow Line and Its Comparison to $\mathrm{Cpm} / \mathrm{Bar}$ Chart Scheduling". Intern. J. of Electr., Mech. and Mechatronics Eng. (IJEMME), 5(1), 891-903.

Sacks, R., Radosavljevic, M., and Barak, R., (2010). "Requirements for building information modeling based lean production management systems for construction". Autom. in Constr., 19(5), 641-655.

Schimanski, C.P., Marcher, C., Dallasega, P., Marengo, E., Follini, C., Rahman, A. U., Revolti, A., Nutt, W., and Matt, D. T. (2018). "Promoting Collaborative Construction Process Management by means of a Normalized Workload Approach.” In: Proc. 26th Annual Conference of the International. Group for Lean Construction (IGLC), González, V.A. (ed.), Chennai, India, pp. 764-774. DOI:doi.org/10.24928/2018/0488Available at: www.iglc.net. 